\title{
FATORES QUE AFETAM A GERMINAÇÃO DAS SEMENTES E A BIOMASSA DE PLÂNTULAS DE Tabebuia heptaphylla
}

\author{
Carlos Alexandre Damasceno Ribeiro ${ }^{1}$, Malcon do Prado Costa $^{2}$, Davi Salgado de Senna ${ }^{3}$, \\ Jônio Pizzol Caliman ${ }^{3}$ \\ ${ }^{1}$ Eng. Florestal. M.Sc.,UFES, Alegre, ES, Brasil \\ ${ }^{2}$ Eng. Florestal, M.Sc., Doutorando em Engenharia Florestal, UFSM, Santa Maria, RS, Brasil - malconfloresta@ gmail.com. \\ ${ }^{3}$ Acadêmicos de Eng. Florestal, Depto. de Engenharia Florestal, UFES, Alegre, ES, Brasil - davissfloresta@ hotmail.com; \\ jpcaliman@hotmail.com
}

Recebido para publicação: 30/01/2009 - Aceito para publicação: 06/05/2010

\begin{abstract}
Resumo
Informações sobre Tabebuia heptaphylla são fundamentais durante a coleta das sementes e produção de mudas. Objetivou-se, no presente estudo, analisar a relação entre os fatores altura de coleta das sementes na planta, peso das sementes, posição da semente no substrato e tipos de substratos com as variáveis germinação de sementes e massa fresca de plântulas. O delineamento experimental utilizado nos 2 experimentos foi o inteiramente casualizado em esquema fatorial composto por tratamentos com 4 repetições de 20 sementes cada. Avaliaram-se duas alturas de coleta das sementes na planta (experimento 1), duas posições das sementes no substrato (experimentos 1 e 2), duas categorias de peso de sementes e quatro tipos de substratos diferentes (experimento 2). Realizados os testes estatísticos, concluiu-se que a altura de coleta, a posição da semente no substrato, o peso das sementes e o tipo de substrato são fatores que atuam isoladamente nas variáveis em estudo. A coleta de sementes de Tabebuia heptaphylla deve ser realizada no terço superior da planta, e a semeadura deve ser feita com as sementes mais pesadas.

Palavras-chave: Semente florestal; germinação; posições nos substratos; peso das sementes; altura de coleta.
\end{abstract}

\begin{abstract}
Factors that affect the germination and development of Tabebuia heptaphylla (Vell.) Toledo: from collect of seeds to seedlings. Information about of Tabebuia heptaphylla can be important for seed collection and seedling production. The objective of this paper is to analyze the relationship between the factors height of harvesting on the tree, weight of seed and the position of seed germination of Tabebuia heptaphylla in the substrate, kind of substrate and the variables seed germination and seedling fresh weight. The entirely randomized experimental design in the factorial scheme, with 4 replicates each with 20 seeds per replicate, was used on 2 experiments. The experimental factors were constituted by 2 height of harvesting (experiment 1) and 2 positions of the seed on the substrate (experiment 1 and 2), 2 categories of weight of seed and 4 kinds of substrates (experiment 2). A statistical test allowed to conclude that the height of seed harvesting, the position of seeds on the substrate, the weight of seeds, the kind of substrate are significant factors. The harvesting of seeds of Tabebuia heptaphylla should be performed in the upper third of the plant and performing sowing of heavier seeds.

Keywords: Forest seed; germination; positions on the substrates; weight of seeds; length of harvesting.
\end{abstract}

\section{INTRODUÇÃO}

As informações inéditas apresentadas neste estudo são valiosas para a coleta de sementes de Tabebuia heptaphylla (Vell.) Toledo em árvores-matrizes, bem como para a produção de mudas e estabelecimento de programas de reflorestamentos diversos.

Tabebuia heptaphylla, chamada popularmente de ipê-roxo, piúva e pau-d`arco, possui distribuição geográfica desde o norte do Brasil (latitude $13^{\circ} \mathrm{S}$ ) até o limite sul (3003' S). Sua madeira, de 
grande valor comercial, é densa e muito utilizada em obras externas, como postes, moirões, dormentes e quilhas de navios. As árvores são muito usadas no paisagismo, devido a sua bela floração durante o inverno (LORENZI, 2002).

Diversos estudos têm testado substratos, temperaturas, tempo de armazenamento e viabilidade de sementes do gênero Tabebuia. Machado et al. (2002), estudando a capacidade germinativa de Tabebuia serratifolia, encontraram experimentalmente a faixa ótima de temperatura entre 25 e $35{ }^{\circ} \mathrm{C}$ para a germinação, sendo esta mais rápida na temperatura próxima a $30^{\circ} \mathrm{C}$, enquanto Santos et al. (2005), estudando a capacidade germinativa de Tabebuia serratifolia (Vahl) Nich, Tabebuia chrysotricha (Mart. ex DC.) Standl. e Tabebuia roseoalba (Ridl) Sand, constataram que essas espécies são indiferentes à luz e possuem faixa de temperatura ótima entre 20 e $30{ }^{\circ} \mathrm{C}$ para a germinação. Outros autores estudaram, desde a década de 70, a influência de métodos de secagem, do teor de umidade, do tempo de armazenamento e dos diversos tipos de solo/substrato na porcentagem de germinação (KANO et al., 1978; MIYASAKI; CÂNDIDO, 1978; MELLO; EIRA, 1995).

Contudo, alguns fatores comprovadamente significativos e já estudados em culturas comerciais têm sido negligenciados no estudo de espécies florestais.

Vitti et al. (2003) estudaram as diferentes respostas de desenvolvimento dos grãos de café em função da posição da semente em relação à altura da planta e à posição cardeal dos ramos e luminosidade solar recebida.

Outro aspecto não analisado, muitas vezes, é a posição da semente no substrato. O posicionamento da semente influencia a superfície de contato entre o solo e a semente e, portanto, altera diretamente a entrada de luz, a troca gasosa e a temperatura interna da semente, de tal forma que a posição no substrato influi diretamente na relação da semente com o ambiente, alterando consequentemente o processo de germinação.

Vale et al. (2004), estudando diferentes substratos, concluiu que eles possuem papel fundamental na produção de mudas de qualidade, já que exercem influência marcante na arquitetura do sistema radicular e no estado nutricional das plantas. Os diferentes substratos variam em suas propriedades químicas e físicas em relação a retenção de água, $\mathrm{pH}$, peso sobre a semente e surgimento de microorganismos (BRASIL, 1992).

O tamanho da semente (o estádio de diferenciação do embrião e a reserva de alimentos) influencia a capacidade germinativa (LARCHER, 2004), que está relacionada à qualidade máxima da semente, conhecida como maturidade fisiológica (EGLI, 1998). Normalmente, para a germinação de diferentes espécies, é recomendado o uso de determinada temperatura e tipo de substrato ideal, além da luz que pode ser requerida.

Diante do exposto, o objetivo geral do trabalho foi aperfeiçoar a coleta de sementes em árvores individuais e descobrir a melhor estratégia para semeadura da espécie Tabebuia heptaphylla. Os objetivos específicos foram: investigar o efeito da altura de coleta das sementes na copa da planta-mãe, dos diferentes substratos, do posicionamento da semente no substrato e do peso das sementes na germinação e na produção de massa fresca. Dessa forma, foram testadas as seguintes hipóteses: (1) sementes coletadas em maiores alturas na copa da árvore possuem maior potencial de germinação; (2) o tipo de substrato, a posição da semente no substrato e o peso da semente apresentam interações entre si e são fatores determinantes para a germinação das sementes e produção de massa fresca das plântulas.

\section{MATERIAL E MÉTODOS}

Em setembro de 2007, foram coletadas sementes de oito árvores pertencentes à arborização urbana do município de Alegre (ES). As sementes procederam de árvores sadias e adultas, distribuídas em três pontos do município, que apresenta uma altitude média de $250 \mathrm{~m}$ e está localizado próximo às coordenadas geográficas de latitude $20^{\circ} 45^{\prime} 49^{\prime \prime} \mathrm{S}$ e longitude $41^{\circ} 31^{\prime} 58^{\prime \prime} \mathrm{W}$. O clima é classificado como do tipo Aw, segundo Köppen, apresenta verões quentes e úmidos e invernos secos, temperatura anual média de $23,1^{\circ} \mathrm{C}$ e precipitação anual em torno de $1.200 \mathrm{~mm}$.

Os frutos foram colhidos maduros, ainda na árvore, e expostos ao sol durante um período de 6 a 8 horas, para liberação espontânea das sementes. As sementes de ipê-roxo foram armazenadas durante 43 dias em câmara fria, à temperatura média de $12{ }^{\circ} \mathrm{C}$ e umidade relativa do ar em torno de $50 \%$, condição suficiente para que não perdessem sua capacidade germinativa, que perdura por até 15 meses 
(KAGEYAMA et al., 1992), ou aproximadamente 600 dias, em condições semelhantes $\left(10^{\circ} \mathrm{C}\right.$ em vidro hermético) (MAEDA; MATTES, 1984).

Foram conduzidos dois experimentos no laboratório de Dendrologia e Sementes Florestais do Núcleo de Estudos e de Difusão de Tecnologia em Floresta, Recursos Hídricos e Agricultura Sustentável (NEDTEC) do Centro de Ciências Agrárias da UFES (CCA/UFES). Os experimentos foram realizados num período de 15 dias. Os substratos utilizados nos dois experimentos foram previamente esterilizados durante 24 horas a $130{ }^{\circ} \mathrm{C}$ em estufa. Cada tratamento foi composto por 4 repetições de 20 sementes cada, sem utilização de biocidas.

Para a análise estatística dos dois experimentos, foi utilizado o teste $\mathrm{F}$ a $5 \%$ de probabilidade, para avaliar a significância dos fatores e de suas interações nas variáveis analisadas. As médias foram comparadas pelo teste de Tukey a $5 \%$ de probabilidade, utilizando-se o programa computacional ASSISTAT (2008).

\section{Experimento 1}

$\mathrm{O}$ experimento foi conduzido segundo um delineamento experimental inteiramente casualizado, em esquema fatorial $2 \times 2$, sendo duas alturas de coleta de sementes (porções inferior e superior da copa, conforme ilustrado na figura 1 , e duas posições de semeadura no substrato - sobre e entre o substrato a $0,5 \mathrm{~cm}$ de profundidade), totalizando 4 tratamentos.

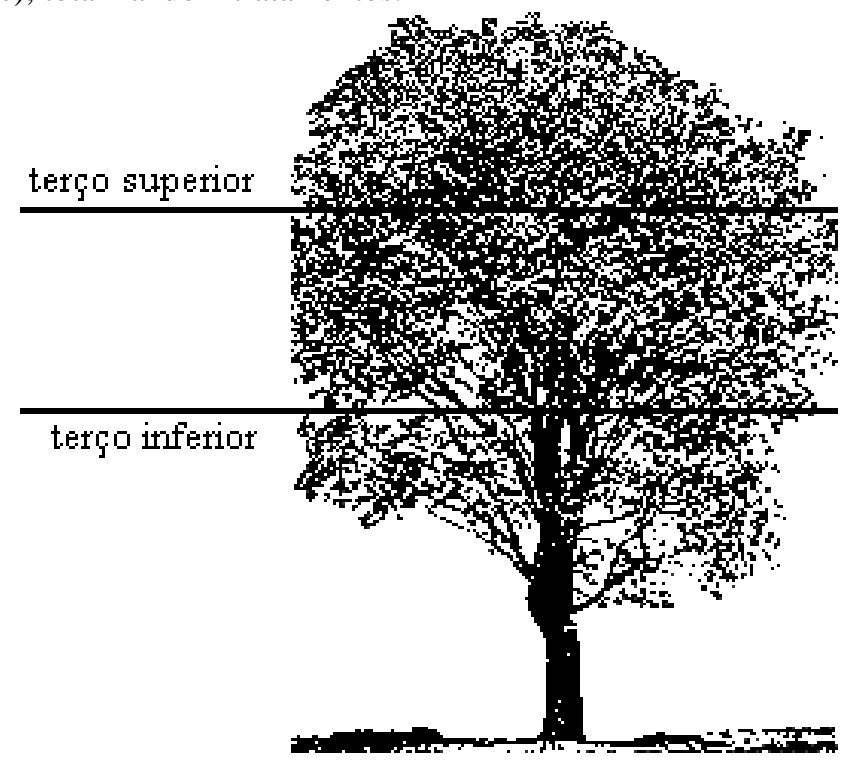

Figura 1. Ilustração do fator altura de coleta de sementes e seus 2 níveis, porção superior e inferior. Figure 1. The 2 levels of seed collection: upper and lower portion.

Os testes de germinação foram conduzidos em germinador tipo Mangelsdorff, à temperatura constante de $30^{\circ} \mathrm{C}$, umedecidas a cada 72 horas e com exposição constante à luz de lâmpadas fluorescentes brancas. Foi utilizada como substrato areia grossa.

A característica avaliada foi a porcentagem de germinação. Realizaram-se 6 contagens a partir do $5^{\circ}$ até o $15^{\circ}$ dia, onde foram consideradas germinadas as sementes com protusão da raiz primária.

\section{Experimento 2}

$\mathrm{O}$ experimento 2 foi realizado com sementes coletadas na melhor posição indicada no experimento 1, sendo conduzido segundo um delineamento experimental inteiramente cazualizado, em esquema fatorial $4 \times 2 \times 2$, sendo quatro tipos de substratos: areia grossa (A), mistura de terra + areia + esterco (TAE, em proporções iguais), vermiculita (V) de granulometria fina e substrato comercial SoloMax (SM); duas posições de sementes no substrato: sobre o substrato (S) e entre o substrato (E) na profundidade de $0,5 \mathrm{~cm}$; e duas categorias de peso de sementes: sementes de até 0,1 grama (P1) e acima 
de $0,1 \mathrm{~g}(\mathrm{P} 2)$, totalizando 16 tratamentos. As sementes foram expostas à temperatura constante de $30^{\circ} \mathrm{C}$ em câmaras do tipo BOD, equipadas com lâmpadas fluorescentes brancas com fotoperíodo simulado de 12 horas, umedecidas a cada 48 horas.

As características avaliadas foram a porcentagens de germinação e a massa fresca de plântulas. Para avaliar a germinação, realizaram-se 6 contagens, a partir do $5^{\circ}$ até o $15^{\circ}$ dia, sendo consideradas germinadas as sementes com protrusão da raiz primária. Quanto à massa fresca de plântulas, as mudas foram retiradas dos substratos, lavadas em água corrente para retirada dos resíduos retidos nas raízes e então deixadas para escorrer até a secagem sobre papel absorvente, para posterior pesagem. Os resultados foram expressos em gramas por planta.

\section{RESULTADOS E DISCUSSÃO}

\section{Experimento 1}

As sementes começaram a germinar a partir do $5^{\circ}$ dia, contrariando a expectativa inicial que indicava germinação ocorrendo entre 10 e 12 dias após a semeadura (LORENZI, 2002).

A análise da variância do esquema fatorial revelou significância somente para o fator altura de coleta dos frutos na planta. Assim, a posição da semente no substrato e a interação entre os fatores coleta de altura x posição da semente no substrato não se revelaram significativos na análise estatística (Tabela 1).

Tabela 1. Fatores e interações entre fatores significativos para germinação de sementes.

Table 1. Factors and interaction of factors significant for germination of seeds.

\begin{tabular}{lc}
\hline Fatores e interação entre fatores & Germinação \\
\hline Altura de coleta & $*$ \\
Posição & NS \\
Altura de Coleta x Posição & NS \\
\hline *: Significativo a 5\% de probabilidade pelo teste F; NS: não significativo.
\end{tabular}

A altura de coleta, pouco estudada em espécies florestais, é um fator significativo e influi na germinação de Tabebuia heptaphylla. Foram encontrados valores médios de germinação de 41,9\% para sementes coletadas de frutos situados no terço superior da planta contra 9,4\% para sementes coletadas de frutos do terço inferior.

Esse fator também foi considerado importante em Coffea arabica. Quando se comparam frutos coletados no terço inferior com aqueles coletados no terço superior da copa, encontram-se diferenças para o rendimento intrínseco do café, ligadas à maturação dos grãos (GASPARI-PEZZOPANE et al., 2005).

O fator posicionamento dos frutos na planta foi abordado de outra forma por Vitti et al. (2003), que constataram que as posições dos frutos em função dos pontos cardeais é fator significativo em relação ao número de flores de "laranja-valência" e concluíram que para o quadrante oeste ocorre o maior número de flores, enquanto que para o quadrante sul o menor.

Em todos os casos citados anteriormente, o fator posicionamento das flores e frutos na copa influi na característica avaliada, podendo haver relação direta com a quantidade e/ou qualidade de radiação solar incidente nas diferentes posições da copa.

Quanto à posição da semente no substrato, não foram encontradas influências na germinação da espécie. Em relação ao tipo de substrato, resultados semelhantes aos constatados no experimento 1 foram encontrados por Bochese et al. (2008), que constataram mais de 50\% de germinação para Tabebuia heptaphylla sobre o substrato areia. Degan et al. (1997), analisando métodos de secagem na conservação, constataram apenas 56,5\% de germinação para Tabebuia roseoalba.

\section{Experimento 2}

As sementes começaram a germinar a partir do quinto dia e obtiveram até $100 \%$ de germinação no $15^{\circ}$ dia, valores mais elevados do que os encontrados para Tabebuia heptaphylla no trabalho realizado por Carvalho (2003), no qual observou 80\% de germinação entre 7 e 30 dias.

A análise da variância do esquema fatorial (Tabela 2) revelou influência do peso da semente e do substrato utilizado na germinação das sementes. Sendo que nenhuma interação entre variáveis influenciou a germinação de sementes. Enquanto para a massa fresca das sementes, além das variáveis, peso da 
semente e tipo de substrato, a posição da semente no substrato também influenciou a massa fresca das sementes. As variáveis, peso da semente e tipo de substrato, foram às únicas que apresentaram interação significativa entre si, exercendo influencia na massa fresca das sementes.

Tabela 2. Fatores e interações entre fatores significativos para germinação e massa fresca de plântulas.

Table 2. Factors and interaction of factors significant for germination and the fresh weight of seedlings.

\begin{tabular}{lcc}
\hline Fatores e interações entre fatores & Germinação (\%) & Massa fresca \\
\hline Peso & $*$ & $*$ \\
Posição & NS & $*$ \\
Peso x Posição & NS & NS \\
Substrato & $*$ & $*$ \\
Peso x Substrato & NS & $*$ \\
Posição x Substrato & NS & NS \\
Posição x Peso x Substrato & NS & NS \\
\hline
\end{tabular}

*: Significativo a $5 \%$ de probabilidade pelo teste F; NS: não significativo.

Para a variável germinação não houve interação entre os fatores substrato, posição e peso, indicando que esses fatores atuam independentemente na porcentagem de germinação. Entretanto, os fatores peso e substratos interferem independentemente na porcentagem da germinação.

Em relação ao fator peso, foram encontrados valores elevados de germinação para sementes mais pesadas (Tabela 3). Denota-se que as substâncias de reservas das sementes influenciam a germinação de Tabebuia heptaphylla.

De acordo com Bewley e Black (1985), as substâncias de reserva são acumuladas para fornecimento de energia e substâncias básicas para o desenvolvimento do processo de germinação. Durante a germinação, as substâncias de reserva são mobilizadas para a produção de energia e de novas moléculas para o crescimento e desenvolvimento das plântulas.

Tabela 3. Resultados de porcentagem de germinação de plântulas de Tabebuia heptaphylla nos dois pesos. Table 3. Results of percentage of germination of Tabebuia heptaphylla in two weigths.

\begin{tabular}{lc}
\hline Pesos & Germinação (\%) \\
\hline P1 & $63,91 \mathrm{a}$ \\
P2 & $86,56 \mathrm{~b}$ \\
\hline \multicolumn{2}{l}{ Médias seguidas pela mesma letra nas linhas não diferem entre si pelo teste de Tukey a 5\% de } \\
probabilidade.
\end{tabular}

Quanto ao substrato, foi perceptível que o TAE, em conjunto com substratos areia e vermiculita (Tabela 4), propiciou os maiores percentuais de germinação. O fator orgânico, que para o substrato TAE utilizado é o esterco na fração de um terço, possivelmente explica seu bom desempenho, sendo um fator que merece ser investigado em experimentos futuros para o gênero Tabebuia, pois Cunha et al. (2005) encontraram resultados análogos estudando Tabebuia impetiginosa. Sob aquelas circunstâncias, ficou evidenciado que as sementes germinadas em terra de subsolo + composto orgânico obtiveram maior desempenho do que as germinadas somente em terras de subsolo, resultados corroborados pelos experimentos realizados por Bocchese et al. (2008), que encontraram o maior percentual de germinação para Tabebuia heptaphylla em solo do tipo argila + matéria orgânica.

Os valores de germinação alcançados nos tratamentos experimentais citados anteriormente estão conexos com os encontrados em literatura para o gênero. Em experimentos controlados, Maeda e Matthes (1984), testando a viabilidade de sementes de Tabebuia heptaphylla ao longo de 30 meses, alcançaram um valor máximo de germinação em torno de $80 \%$ para sementes recém-colhidas. Oliveira et al. (2006) encontraram $90 \%$ de germinação para Tabebuia aurea 30 dias após coleta.

Para a variável massa fresca de plântulas, houve interação entre os fatores peso da semente e substrato, enquanto a posição da semente no substrato atuou de forma independente na porcentagem de germinação. 
Tabela 4. Resultados de porcentagem de germinação de plântulas de Tabebuia heptaphylla nos diferentes substratos.

Table 4. Results of percentage of germination of Tabebuia heptaphylla in different substrates.

\begin{tabular}{lc}
\hline Substratos & Germinação (\%) \\
\hline Areia & $80,00 \mathrm{a}$ \\
TAE & $84,00 \mathrm{a}$ \\
Vermiculita & $76,56^{\mathrm{a}}$ \\
SoloMax & $59,68 \mathrm{~b}$ \\
\hline Médias seguidas pela mesma letra nas linhas não diferem entre si pelo teste de Tukey a 5\% de \\
probabilidade.
\end{tabular}

Em relação ao fator peso, houve diferença quando relacionado ao substrato areia, em que se pode perceber que sementes mais pesadas produziram em média $5,40 \mathrm{~g}$ de massa fresca, enquanto que sementes mais leves produziram somente $3,76 \mathrm{~g}$ (Tabela 5). Os outros três substratos não apresentaram diferenças no fator peso da semente, o que pode ser explicado pelo fato de a areia ser o substrato com maior restrição à planta para absorver nutrientes em relação à TAE e vermiculita. Assim, a capacidade de sucesso do indivíduo com investimento em recursos de crescimento torna-se mais dependente das substâncias de reserva nesse tipo de substrato. O SoloMax foi o de menor massa fresca em relação aos outros e não foi distinguível em relação ao fator peso. As sementes germinadas nos melhores substratos (areia, TAE e vermiculita) produzem mais massa fresca de plântulas em comparação com o SoloMax.

Tabela 5. Resultados de massa fresca de plântulas de Tabebuia heptaphylla para os pesos de sementes nos diferentes substratos.

Table 5. Results of mass of seedlings of Tabebuia heptaphylla, in different weight of seeds and different substrates.

\begin{tabular}{lcccc}
\hline \multirow{2}{*}{ Peso } & \multicolumn{5}{c}{ Substratos } \\
\cline { 2 - 5 } & Areia & TAE & Vermiculita & SoloMax \\
\hline P1 & $3,76 \mathrm{bB}$ & $4,01 \mathrm{bA}$ & $3,37 \mathrm{bB}$ & $0,25 \mathrm{aC}$ \\
P2 & $5,40 \mathrm{aA}$ & $5,35 \mathrm{aA}$ & $4,47 \mathrm{aB}$ & $0,27 \mathrm{aC}$ \\
\hline
\end{tabular}

Médias seguidas pela mesma letra minúscula nas colunas e maiúscula nas linhas não diferem entre si pelo teste de Tukey a 5\% de probabilidade.

A posição da semente no substrato influenciou a produção de massa fresca. Sementes posicionadas entre o substrato produziram 3,44 gramas de massa fresca, enquanto sementes sobre o substrato produziram somente $3,28 \mathrm{~g}$. Oliveira et al. (2006) estudaram a posição da semente em relação ao substrato para Tabebuia aurea e concluíram que a estimativa de germinação em campo que apresentou melhor resultado foi para sementes na superfície do solo.

Tabela 6. Resultados de massa fresca de plântulas de Tabebuia heptaphylla nas posições sobre e entre os substratos.

Table 6. Results of mass of seedlings of Tabebuia heptaphylla in positions between and above substrates.

\begin{tabular}{lc}
\hline Posição da semente & Massa fresca \\
\hline Entre (E) & $3,44 \mathrm{a}$ \\
Sobre (S) & $3,28 \mathrm{~b}$ \\
\hline Médias seguidas pela mesma letra nas linhas não diferem entre si pelo teste de Tukey a 5\% de \\
probabilidade.
\end{tabular}

A interação entre os fatores peso e substrato é complexa, podendo potencializar o desenvolvimento de sementes de Tabebuia heptaphylla não só por ocasião da germinação, mas com efeito persistente durante o desenvolvimento e estabelecimento da plântula ao longo do tempo. Os fatores podem ainda agir de forma compensatória ou não, como ilustrado para o substrato SoloMax, em que o fator peso não compensou a deficiência do fator substrato. Andrade e Paulino (1995) constataram um tipo de mecanismo compensatório em relação ao tamanho das sementes (indica maturidade fisiológica, $a$ priori) de Euterpe edullis. Concluíram que o tamanho da semente não influencia a velocidade de 
emergência, mas o vigor das plântulas, sendo que sementes grandes apresentaram maior desenvolvimento de raiz e parte aérea. Talvez por esse motivo germinem relativamente mais vagarosamente.

Os resultados apresentados neste estudo, em conjunto com os estudos supracitados, permitem levantar a hipótese de que, mesmo sob condições semelhantes, sementes de espécies florestais com formação genética e fisiológica muito próxima (da mesma espécie, ou gênero, por exemplo) podem apresentar porcentagens de germinação muito distintas, ora devido às condições experimentais diferentes, ora devido às condições ainda não analisadas experimentalmente, como procedência das sementes, maturidade fisiológica da árvore-mãe, maturidade fisiológica das sementes, condições climáticas durante a geração dos frutos/sementes (fenologia) e a posição do fruto na árvore ou em relação ao movimento aparente do sol ao longo do dia (posições cardeais). Fatores que se sabe, empiricamente, que influem diretamente na maturação/desenvolvimento dos frutos/sementes.

Essa constatação é importante para orientar novas investigações científicas que busquem as condições laboratoriais mínimas, aplicadas de forma particularizada para cada gênero, ou grupo de gêneros, de essências florestais e também fatores outros que os já especificados nas regras e metodologias de análise de sementes em voga.

\section{CONCLUSÕES}

- Recomenda-se realizar coleta de sementes de Tabebuia heptaphylla no terço superior da planta, pois elas apresentam maior porcentagem de germinação.

- As sementes mais pesadas de Tabebuia heptaphylla produzem mais massa fresca e apresentam maiores porcentagens de germinação. Assim, recomenda-se classificar as sementes em função do peso, para garantir produção de mudas de maneira mais homogênea no viveiro.

- O posicionamento das sementes no substrato influencia a produção de massa fresca, sendo recomendável que a semente seja posicionada entre o substrato na profundidade de $0,5 \mathrm{~cm}$, para se alcançar melhor desenvolvimento das plântulas em viveiro.

- Recomenda-se o uso de três substratos, a composição terra + areia + esterco, apenas areia e a vermiculita, pois foram os substratos que propiciaram as melhores germinações das sementes de Tabebuia heptaphylla, sendo indicados para a produção de mudas em viveiros e/ou laboratórios, por serem eficientes e de fácil aquisição.

\section{REFERÊNCIAS}

ANDRADE, A. C. S.; PAULINO, M. T. S. Efeito da massa da semente na velocidade de germinação e no desenvolvimento de plântulas de Euterpe edulis Mart. (palmiteiro). Londrina: ABRATES. Informativo Abrates. v. 5, n. 2, 1995, p. 189.

ASSISTAT Versão 7.5 beta. Francisco de Assis S. e Silva. Departamento de Engenharia Agrícola. Centro de Tecnologia e Recursos Naturais. Universidade Federal de Campina Grande. Campina Grande, PB. 2008.

BEWLEY, J. D.; BLACK, M. Seeds: Physiology of development and germination. New York: Plenum Press, 1985, $367 \mathrm{p}$.

BOCCHESE, R. A.; OLIVEIRA, A. K. M.; MELOTTO, A. M.; FERNANDES, V.; LAURA, V. A. Efeito de diferentes tipos de solos na germinação de sementes de Tabebuia heptaphylla em casa telada. Revista Cerne, Lavras, v. 14, n. 1, p. 62 - 67, jan./mar. 2008.

BRASIL. Ministério da Agricultura e Reforma Agrária. Regras para análise de sementes. Brasília, 1992. p. 365.

CARVALHO, P. E. R. Espécies arbóreas brasileiras. Colombo: Embrapa Florestas, 2003. v. 1, 1039 p.

CUNHA, A. O.; ANDRADE, L. A.; BRUNO, R. L. A.; SILVA, J. A. L.; SOUZA, V. C. Efeitos de substratos e das dimensões dos recipientes na qualidade das mudas de Tabebuia impetiginosa (Mart. Ex DC.) Standl. Revista Árvore, v. 29, n. 4, p. 507 - 516, 2005. 
DEGAN, P.; AGUIAR, I. B.; SADER, R.; PINTO, L. R. Composição química, sanidade, secagem e germinação de sementes de ipê-branco (Tabebuia roseoalba (Ridl.) Sand. Bignoniaceae). Revista Brasileira de Horticultura Ornamental, Campinas, v. 3, n. 1, p. 41 - 47, 1997.

GASPARI-PEZZOPANE, C.; FILHO, H. P. M.; BORDIGNON, R.; SIQUEIRA, W. J.; AMBRÓSIO, L. A.; MAZZAFERA, P. Influências ambientais no rendimento intrínseco do café. Bragantia, Campinas, v. 64, n. 1, p. 39 - 50, 2005.

KAGEYAMA, P. Y.; SANCHEZ, S. P. A.; FERRAZ, E. M.; SOUZA, L. M. C. Armazenamento de sementes de três espécies nativas (Tabebuia heptaphylla, Erytrhina verna e Chorisia speciosa). Revista do Instituto Florestal, São Paulo, v. 4, p. 435 - 439, 1992.

KANO, N. K.; MÁRQUEZ, F. C. M.; KAGEYAMA, P. Y. Armazenamento de sementes de ipê-dourado (Tabebuia sp.). Instituto de Pesquisa e Estudos Florestais, Piracicaba, n. 17, p. 13 - 23, 1978.

LARCHER, W. Ecofisiologia vegetal. São Carlos: Rima, 2004. p. 125 - 130.

LORENZI, H. Árvores brasileiras: manual de identificação e cultivo de plantas arbóreas nativas do Brasil. Nova Odessa: Instituto Plantarum de Estudos da Flora, 2002. v. 1, 368 p.

MACHADO, C. F.; OLIVEIRA, J. A.; DAVIDE, A. C.; GUIMARÃES, R. M. Metodologia para a condução do teste de germinação em sementes de ipê-amarelo (Tabebuia serratifolia (Vahl) Nicholson). Revista Cerne, v. 8, n. 2, p. 17 - 25, 2002.

MAEDA, J. A.; MATTHES, L. A. F. Conservação de sementes de ipê. Bragantia, Campinas, v. 43, n. 1, p. $51-61,1984$.

MELLO, C. M. C.; EIRA, M. T. S. Conservação de sementes de ipês (Tabebuia spp.). Revista Árvore, Viçosa, v. 19, n. 4, p. 427 - 432, 1995.

MIYASAKI, J. M.; CÂNDIDO, J. F. Secagem de sementes de ipê-amarelo (Tabebuia serratifolia Vall/Don). Revista Seiva, Viçosa, n. 85, p. 12 - 17, 1978.

OLIVEIRA, A. K. M.; SCHLEDER, E. D.; FAVERO, S. Caracterização morfológica, viabilidade e vigor de sementes de Tabebuia aurea (Silva Manso) Benth. e Hook. f. ex. S. Moore. Revista Árvore, ViçosaMG, v. 30, n. 1, p. 25 - 32, 2006.

SANTOS, D. L. DOS; SUGAHARA, V. Y.; TAKAKI, M. Efeitos da luz e da temperatura na germinação de sementes de Tabebuia serratifolia (Vahl) Nich, Tabebuia chrysotricha (Mart. ex DC.) Standl. e Tabebuia roseoalba (Ridl) Sand - Bignoniaceae. Ciência Florestal, Santa Maria, v. 15, n. 1, p. 87 - 92, 2005.

VALE, L. S. do; COSTA, J. V. T. da; ANUNCIAÇÃO FILHO, C. J. da; LIMA, R. L. S. Efeito de diferentes misturas de substrato e tamanho de recipientes na produção de mudas de mamoeiro. In: BARBOSA, J. G.; MARTINEZ, H. E. P.; PEDROSA, M. W. Nutrição e adubação de plantas cultivadas em substrato. Viçosa: UFV, 2004. p. 385.

VITTI, M. R.; DE ROSSI, A.; RUFATTO, L.; VISENTIN, M.; MENDEZ, M. H. G. Época e intensidade de florescimento da laranja valência enxertada sobre dois porta-enxertos de acordo com a distribuição pelos quadrantes em três ciclos produtivos. Revista Brasileira de Agrociência, v. 9, n. 4, p. 343 - 346, 2003. 